\title{
Exploration of Psychological Perspective in Building of Happy and Livable Langfang
}

\author{
Juanwei Li, Jingang Yang \\ North China Institute of Aerospace Engineering, Langfang, 065000, China
}

Keywords: happy and livable, urban construction, Langfang, psychology, paths

\begin{abstract}
In recent years, there are increasingly more researches on happiness at home and abroad, and building happy and livable cities has become an important standard of urban construction. As a city with a long history and culture in China, Langfang has obtained considerable achievements in happy and livable urban construction, and has new strength in terms of urban construction, and has built a number of landmark buildings and urban symbols, and has prototype of ecological, modern and intelligent city districts. This paper briefly analyzes psychological perspective in building of happy and livable Langfang City, describes construction achievements of current happy and livable Langfang City, analyzes psychological theoretical foundation of building of a happy and livable city, and analyzes construction paths of happy and livable Langfang City from a psychological perspective.
\end{abstract}

\section{Introduction}

To increase happiness index and build a livable city, more attention shall be paid to people's livelihood, which is the foundation of harmony. Only by being always concerned about people's livelihood and constantly improving people's livelihood, can the most concerned, the most direct and the most practical interest problems of people be practically solved, and thus people could feel happiness brought by development. To increase happiness index and build a livable city, habitat environment shall be optimized. The improvement of habitat environment is the premise of increasing people's happiness index. Urban construction management level shall be improved constantly, and an environment that is suitable for habitat, entrepreneurship and development shall be created. To increase happiness index and build a livable city, security and stability shall be maintained. Practice indicates that people yearn for stability and hope peace. Stability is the foundation of development, and nothing can be done without a stable environment.

In 2011, the Fifth Langfang Congress of Party Representatives proposed "Eight Langfangs" as construction goals of the next five years, took "building a harmonious society and happy Langfang" as the ultimate foothold of municipal economy and development and one of key tasks during the “ $12^{\text {th }}$ Five-Year Plan". In January 2014, Langfang held the Sixth Plenary Session (Enlarged) of the Fifth CPC Central Committee, which clearly put forward three basic positioning of Langfang urban construction namely green development, high-end development and leading development, determined four major city cards namely plain forest city, environmental industry city, cultural experience city, and happy and livable city, and realized vigorously great breakthroughs in terms of park construction, project construction, private economic development and innovative institutional mechanism.

\section{Phased achievements of Langfang's vigorous building of a happy and livable city}

Langfang has obtained phased achievements in building of a happy and livable city, and has built New Langfang City and Langfang Deputy Central City with complete infrastructure, high-quality resource sharing and rural-urban development, and adheres to same standards, construction and interactive development with Langfang City and construction of development of new cities and renovation of reconstruction of old cities. Cities extend a new pattern, build a large outer county ring, create Langba Road Featured Scenic Route, and give modern atmosphere to good ecological environment. Urban construction highlights new strength, and builds a number of landmark buildings and urban symbols. Ecological, modern and intelligent cities are in an early form. With 
representatives of Lilancheng Town and Hancun Town, a number of modern little towns with prosperous economy, complete functions and distinctive features have been built. Continue to promote new rural construction actively and stably and develop new communities.

Happy rural construction of Langfang City has the core of increasing peasants' income and the primary task of improving peasants' living conditions, and creates a number of happy villages with reasonable layout, complete facilities, beautiful environment and peaceful life and work. Happy rural construction is carried out from four perspectives namely improvement of health environment, demonstration and guidance of key regions, promotion of comprehensive supporting facilities and community brand. Among these, health environment is the key of happy and livable rural construction, and thus dirty, disorderly and bad rural conditions are completely changed, health exposed trash-dropping places and health dead areas in rural areas are completely eliminated, and thus peasants' living and production environment obtains great improvement. Vigorously promote road engineering, drinking water engineering and health room engineering etc, and improve infrastructure in rural areas. For example, Langfang has not surface water, and rural areas have prominent problems in drinking water safety. Thus, this city specially establishes rural drinking water safety construction project command department, all levels of party committees and governments reduce daily expenses, and focus funds on construction of water supply plants among villages. Secretaries of county (municipal, district) Party Committee and county heads (mayors, wardens) serve personally as engineering construction commanders, coordinate all forces to accelerate the progress of water plant construction, and solve peasants' drinking water safety problems, solidify existing community achievements, provide a high-standard service system, build new modern rural communities, and create happy villages with Langfang characteristics. To realize income growth of rural areas, support vigorously the development of rural supporting industries and competitive industries, improve production capability of rural areas, promote vigorously rural economic construction and improve peasants' income and living standards.

\section{Psychological theoretical foundation of construction of happy and livable Langfang}

\subsection{View of happiness in humanistic psychology}

Happiness is psychologically defined as an emotional state that individuals realize that their needs are satisfied and their dreams have come true, while view of happiness in humanistic psychology can reflect people-oriented values the most, takes happiness as subjective feeling of individuals namely a sense of satisfaction generated after people are satisfied. Such view of happiness is based on people, and defines happiness as individuals' experiential, rational and emotional grasp of their needs and satisfaction state, evaluates people's sense of happiness, and attaches importance to individuals' psychological feelings rather than changing people's sense of happiness into figures, which is very necessary for construction of happy and livable cities. It can guide relevant departments to understand people's psychological needs, grasp key points of construction of happy and livable cities, and master the connotation of happy and livable cities.

\subsection{Positive psychology}

Positive psychology is a new ideological trend sprung up in the end of 20th century, and is contrary to traditional negative psychology, and emphasizes concern about psychological status of ordinary people and people's virtues and potential, guides people to give play to positive factors of confidence, love and virtues etc, realizes individual and social progress, leads people to happiness, and believes that the ultimate goal of human development is happiness. The construction of happy and livable Langfang City has also the goal and ultimate foothold of people obtaining a sense of happiness, which is just consistent with the core of positive psychology. Thus, positive psychology is also one of important psychological and theoretical bases of the construction of happy and livable cities. Positive psychology believes that: happiness is not given by the government, but a common goal of individual and social pursuit, happiness shall attach importance to the positive role of an objective factor as individuals' subjective active emotional experience which objectively exists. Happiness shall have certain practical significance rather than people's subjective assumption, and happiness without objective basis is illusory. Therefore, the construction of happy and livable 
Langfang City shall focus on people's livelihood engineering, link closely with practice, and establish multiple goals that can be realized in order to be socially recognized. For example, establish a general goal of "built-up modern city" objectively; and a featured goal of building "a historical city with Langfang cultural characteristics"; and take people's "high sense of identity, high degree of satisfaction, and strong sense of belonging” as core goals subjectively.

3.3 Two-way Interaction Relationship Theory Hypothesis

There is a two-way interaction relationship between people's sense of happiness and cities, as cities not only restrict people's life and survival and affect changes in people's sense of happiness, but also provide a dependent environment for progress of human society. People's recognition, needs and behaviors stimulate changes in cities, and are driving forces of urban development. So, there is a two-way interaction relationship between people's sense of happiness and cities. Two-way Interaction Relationship Theory Hypothesis in psychology was proposed in 2010, urban construction affected people's sense of happiness, while people's sense of happiness was one of important indicators of urban construction.

\subsection{Subjective well-being}

Subjective well-being is individuals' overall evaluation of quality of life according to their own standards, and is individuals' evaluation of whether they are happy, including times that people experience pleasant and unpleasant emotions. With a higher degree of overall satisfaction, individuals will have more positive emotions and stronger subjective well-being. Subjective well-being is highly subjective, holistic and relatively stable. In previous researches on well-being, scholars focus on study of group well-being, link group well-being with urban construction, and study more on subjective well-being of some elderly people, citizens and college students etc, but less on that of special groups such as the disabled, special professionals and single-parent children. However, individuals' subjective well-being has influence on group well-being. Psychological researches of urban construction shall also focus on investigation and study of subjective well-being of special groups and individuals, give full play to the active role of factors in improving individuals' subjective well-being, and promote the construction of happy and livable cities.

\section{Exploration of psychological effects and paths of expanding the construction of happy and livable Langfang City}

Construction of Happy and livable Langfang is to combine closely with current situation of urban construction, center on urban planning, grasp people's psychological needs, take objective indicators as the foundation and realizing subjective indicators as goals, conduct people-oriented urban construction, give full play to the positive influence of policies on people's psychology, and promote the construction of happy and livable city. From a psychological perspective, the construction of happy and livable Langfang City can be commenced from the following four aspects:

4.1 Attach importance to people's psychological feelings

The first project of building happy and livable Langfang is a huge project of people's livelihood, and thus shall have correct localization of people's livelihood project, take supporting beneficial measures, achieve co-construction and sharing, make clear that happiness is not a gift but an obligation of the government, motivate all available internal and external causes and social forces, and encourage people to participate actively in construction of people's livelihood project. Construction of happy and livable Langfang shall win recognition and support of people, mobilize subject consciousness of floating population and non-native population, and make people accept the government's people's livelihood project psychologically, to lay a solid foundation for forming good atmosphere of people's livelihood project with government guidance, social participation and individual efforts. As the construction of a happy and livable city is a huge and long-term project, there would always be difficulties, disputes and questions, while the government and society shall always have a firm stand and will, strive actively in setbacks, do not be anxious for success, and construct step by step, analyze problems during construction and reasons of the difference between construction achievements and predetermined goals, revise and perfect indicator system timely, 
adjust policies, make residents feel urban changes, win social recognition and thus promote the construction of happy and livable Langfang.

4.2 Attach importance to construction of cultural atmosphere and form correct psychological orientation

Culture is people's spiritual bond. Langfang is a city with a long history and culture, and cultural construction is conducive to enhancing charm and appeal of this city. Thus, the construction of happy and livable Langfang shall start with reform of cultural system, and give play to the leading and psychological guiding role of culture in urban construction, promote the development of culture industry vigorously, realize transformation and upgrading of culture industry, and build a strongly cultural city. Explore the charm of Langfang's united-front culture fully, give play to its important role in construction of harmonious socialist society, absorb the essence of external cultures, and make Langfang culture more featured. Attach importance to the construction of a public cultural service system, do well in cultural beneficial work, meet cultural needs of all classes of people comprehensively, and highlight Langfang's profound cultural deposits. Cultural construction shall also strengthen guidance of correct values and concept of money, form cultural consensus, take pursuit of happiness as the most important value orientation, affect people's psychology through moral composition and benefits through culture, and improve urban cultural strength, so that Langfang would be unique in materialistic modern urban atmosphere and thus build happy and livable Langfang.

4.3 Strengthen social management and meet people’s living needs

Construction of happy and livable Langfang is not just about growth of GDP, but about needs of all classes of people, which shall be met through appropriate social guidance. People have physiological needs, safety needs, affiliation needs, self-esteem needs and self-breakthrough needs etc, which shall be met by the society through guarantee, stability, toleration, justice and progress etc. Therefore, the construction of happy and livable Langfang shall strengthen social management actively, reflect people-oriented values, make innovation of urban construction ideas and guidelines, sort various social relations, solve social contradictions, accelerate the construction of social security system, create a relaxed and lively social atmosphere and guaranteed public security environment for people's production and life, establish transparent, open and fair government, create a harmonious and stable social situation and fair social environment, protect legal rights and interests of each person, meet living needs of each person, enhance people's sense of happiness fundamentally and build a happy and livable Langfang.

4.4 Attach importance to people's psychological health education and improve their happiness sensibility

Psychological health is one of important indicators of people's sense of happiness. Thus, it shall attach importance to people's psychological health education, strengthen social psychological guidance, guide all classes of people to respond correctly to setbacks and difficulties through publicity and education of psychological health knowledge, construction of psychological health websites, construction of psychological counseling rooms and construction of psychological health rescue rooms etc, improve people's psychological enduring capacity, form healthy, lively, tolerant and self-improvement spirit and state of mind, and realize physical and mental harmony and social harmony. The government helps people establish a healthy view of happiness through a variety of psychological health education, enhances their happiness sensibility, adjusts expected value of happiness, and enables people to pursue happiness actively and enjoy happiness in a reasonable range, makes people feel that happiness is tangible and they would feel and enjoy happiness as long as they devote and feel wholeheartedly and sincerely.

\section{Conclusions}

Construction of happy and livable Langfang City has obtained phased results in terms of both environmental improvement and social and economic development, and has enhanced people's sense of happiness, and is conducive to steady progress of the construction of happy and livable city with Langfang cultural characteristics. The author puts forward several suggestions for construction 
paths of happy and livable city from a psychological perspective with a hope of helping people concerned.

\section{Acknowledgments}

This paper is a research of Langfang Federation of Social Sciences, research name: Study on Construction Countermeasures of Happy and Livable Langfang from A Psychological Perspective, research No.: 2014016. Members of research group are: Li Juanwei, Yang Jingang, Su Hua and Shen Yuanjun.

\section{References}

[1] Qin Panbo, Qin Guiping. Psychological Thoughts on People-oriented Construction of Happy Guangzhou [J]. Exploration, 2012 (4): 20-24.

[2] Chen Bo. Study on the Application of Environmental Psychology in Urban Environment Design-A Case Study of Urban Street Environmental Facility Design [J]. Journal of Anhui Agricultural Sciences, 2012, 40 (10): 6027-6028.

[3] Li Jingjing, Li Chunli. Research Review of College Students' Subjective Well-being [J]. Journal of Luoyang Normal University, 2009, 28 (2): 172-173.

[4] Su Hua, Li Juanwei. New Perspectives of the Construction of Happy Langfang Villages [J]. Intelligence, 2013 (6): 323. 